\title{
DARPP-32 expression arises after a phase of dysplasia in oesophageal squamous cell carcinoma
}

\author{
Y Ebihara*,', M Miyamoto', A Fukunaga', K Kato', T Shichinohe', Y Kawarada', T Kurokawa', Y Cho', \\ S Murakami' , H Uehara', H Kaneko', H Hashimoto', Y Murakami', T Itoh', S Okushiba', S Kondo' and H Katoh' \\ 'Surgical Oncology, Cancer Medicine, Division of Cancer Medicine, Hokkaido University Graduate School of Medicine, NI 5W7 Kita-ku, Sapporo, \\ Hokkaido 060-8638, Japan; ²Department of Pathology, Hokkaido University Hospital, NI 4W7 Kita-ku, Sapporo, Hokkaido 060-8648, Japan
}

This is the first report to correlate DARPP-32 immunoreactivity (dopamine and cAMP-regulated phosphoprotein, $M_{r} 32000$ ) to clinicopathological status in human cancer. DARPP-32 is recognised as a neuronal protein. A recent study demonstrated that DARPP32, and a truncated isoform t-DARPP, are overexpressed in gastric carcinoma during the process of carcinogenesis. The biological function of DARPP-32, however, is still unclear. The purpose of this study was to clarify the roles of DARPP-32 and t-DARPP in oesophageal squamous cell carcinoma (OSCC). Initially, we investigated DARPP-32 and t-DARPP expression in OSCC cell lines by Reverse transcription-polymerase chain reaction and Western blot. DARPP-32 expression was observed in four out of seven (57.1\%) cell lines, but t-DARPP expression was not observed in any cell lines. In oesophageal tissue sample, DARPP-32 expression was observed in four out of seven (57.1\%) tumour tissues, while t-DARPP was not observed in any tissues. Subsequently, DARPP expression was assessed by immunohistochemistry, using a polyclonal antibody, in tissue sections from 122 patients with primary OSCC. DARPP immunoreactivity was not observed in any normal oesophageal mucous membranes. On the other hand, positive DARPP immunostaining was detected in 37 patients $(30.3 \%)$ and correlated inversely with pathologic stage $(P=0.0284)$, PT $(P=0.0438), \mathrm{pN}(P=0.0303)$ and tumour size $(P=0.012)$. The overall survival rate was worse in patients with DARPP-negative tumours than in patients with DARPP-positive tumours $(P=0.0453)$. Interestingly, DARPP expression was observed in only one out of 45 cases of dysplasia. These observations suggest that DARPP-32 (rather than t-DARPP) expression arises after a phase of dysplasia in OSCC, and that tumours expressing DARPP-32 progress less rapidly than DARPP-32-negative tumours.

British Journal of Cancer (2004) 91, I19-123. doi:10.1038/sj.bjc.660I899 www.bjcancer.com

Published online 8 June 2004

(c) 2004 Cancer Research UK

Keywords: DARPP-32; oesophageal squamous cell carcinoma; immunohistochemistry; carcinogenesis; prognosis

Oesophageal carcinoma remains a disease with poor prognosis. Advances in surgical technique and perioperative management have improved survival to some extent. The overall 5-year survival rate, however, generally remains less than $50 \%$, even with the use of multimodality therapy (Ando et al, 1997, 2000; Collard et al, 2001). This is despite a better understanding of the molecular basis of oesophageal carcinogenesis and identification of prognostically important biologic markers.

DARPP-32 (dopamine and cAMP-regulated phosphoprotein, $M_{\mathrm{r}}$ $32000)$ is recognised as a neuronal protein. In brain, DARPP-32 is a potent inhibitor of a cell cycle regulatory enzyme, protein phosphatase-1 (PP1) (Bibb et al 1999; Greengard, 2001), and can mediate phosphorylation and activation of mitogen-activated protein kinase (MAPK) and c-AMP-responsive element-binding protein (CREB), an inhibitor of apotosis (Yan et al, 1999). Furthermore, DARPP-32 orchestrates the degree of phosphorylation in a variety of molecular targets in the cell membrane and cytoplasm (Greengard, 2001). DARPP-32 and t-DARPP have been proposed to be factors providing an important survival advantage to neoplastic cells and may be important for gastric tumorigenesis

*Correspondence: Dr Y Ebihara; E-mail: yuma-ebi@wc4.so-net.ne.jp Received II November 2003; revised 17 February 2004; accepted 8 April 2004; published online 8 June 2004
(Wa'el et al, 2002). However, thus far, little is known about the role of DARPPs in carcinogenesis. Here, we examined DARPP-32 and tDARPP expression and immunoreactivity in OSCC cell lines in archival material obtained from 122 surgical specimens of oesophageal squamous cell carcinoma (OSCC) with clinical and histopathologic factors obtained by a retrospective review of patient records.

\section{MATERIALS AND METHODS}

\section{Cell lines and culture conditions}

Human OSCC cell lines TE2, TE5, TE8, TE10 and TE13 were generously provided by $\mathrm{Dr}$ Nishihira (University of Tohoku, Japan). HEC46 was provided by Dr Toge (University of Hiroshima, Japan), and SGF7 was provided by Dr Saito (Toyama Medical and Pharmaceutical University, Japan). TE2, TE5, TE8, TE10, TE13 and HEC46 cells were grown in Dulbecco's modified Eagle's medium (D-MEM, Sigma-Aldrich Co., Ltd., Irvine, CA, USA) with 10\% fetal bovine serum (FBS), and 1\% penicillin/streptomycin (p/s). SGF7 cells were maintained in RPMI-1640 medium (Sigma-Aldrich Co., Ltd.) with $10 \% \mathrm{FBS}$ and $1 \% \mathrm{p} / \mathrm{s}$. All cell lines were maintained in a humidified incubator with $5 \% \mathrm{CO}_{2}$ in air at $37^{\circ} \mathrm{C}$. 


\section{Tissue samples}

Tumour and normal tissue samples were snap-frozen and stored at $-80^{\circ} \mathrm{C}$. The samples were obtained in 2002 from resections directly after surgery. Frozen sections $(5 \mu \mathrm{m})$ were stained with haematoxylin and eosin ( $\mathrm{H} \& \mathrm{E})$ to verify OSCC and approximately $0.1 \mathrm{~g}$ of the tumour block was processed for RNA extraction using the TRIZOL Reagent (GIBCO BRL, Grand Island, NE, USA).

\section{Reverse transcriptase-polymerase chain reaction (RT - PCR)}

Total cellular RNA was isolated with TRIZOL Reagent (GIBCO BRL) from each cell line. Each $20 \mu \mathrm{l}$ cDNA synthesis reaction contained $1 \mu \mathrm{g}$ of total RNA, $1 \times$ First Strand Buffer (GIBCO BRL); $50 \mathrm{~mm}$ Tris-HCL, pH 8.3, $75 \mathrm{~mm} \mathrm{KCL}, 3 \mathrm{~mm} \mathrm{MgCl}_{2}$ ), $0.5 \mathrm{~mm}$ of each deoxynucleotide triphosphate, $200 \mathrm{U}$ of SUPERSCRIPT II (GIBCO $\mathrm{BRL}$ ), $10 \mathrm{~mm}$ dithiothreitol and $0.5 \mu \mathrm{g}$ oligo (dT) (GIBCO BRL). The reverse transcription (RT) reaction was carried out for $50 \mathrm{~min}$ at $42^{\circ} \mathrm{C}$ and inactivated by heating at $70^{\circ} \mathrm{C}$ for $15 \mathrm{~min}$. Multiplex PCR was performed as described previously (Wong et al, 1994). Briefly, each $25 \mu \mathrm{l}$ reaction contained $2 \mu \mathrm{l}$ of RT reaction products, $1 \mathrm{U}$ of Taq DNA polymerase (Boehringer Mannheim, Germany), $1 \times$ PCR buffer (Boehringer Mannheim), $160 \mathrm{~mm}$ of each deoxynucleotide and $20 \mathrm{pmol}$ of each $3^{\prime}$ and $5^{\prime}$ primer specific for DARPP-32 (sense, $5^{\prime}$-gaagatccagttctcgg- $3^{\prime}$; antisense $5^{\prime}$-ACTTAGTGCTGGGTCTTCC-3'), t-DARPP (sense, $5^{\prime}$-gttccggctctcagagca- $3^{\prime}$; antisense $5^{\prime}$-ACTTAGTGCTGGGTCTTCC- $3^{\prime}$ ), and $\beta$-actin (sense, $5^{\prime}$-AATCGTGCGTGACATTTAG- ${ }^{\prime}$; antisense $5^{\prime}$ GTCCACGTCACACTTCATG- $3^{\prime}$ ). DARPP-32, t-DARPP and $\beta$-actin cDNA were amplified for 30 cycles. Conditions for DARPP-32 PCR were $94^{\circ} \mathrm{C}$ for $30 \mathrm{~s}, 52^{\circ} \mathrm{C}$ for $30 \mathrm{~s}$, then $72^{\circ} \mathrm{C}$ for $30 \mathrm{~s}$. Conditions for t-DARPP PCR were $94^{\circ} \mathrm{C}$ for $30 \mathrm{~s}, 53^{\circ} \mathrm{C}$ for $30 \mathrm{~s}$, then $72^{\circ} \mathrm{C}$ for $30 \mathrm{~s}$. Conditions for $\beta$-actin PCR were $94^{\circ} \mathrm{C}$ for $30 \mathrm{~s}, 51^{\circ} \mathrm{C}$ for $30 \mathrm{~s}$, then $72^{\circ} \mathrm{C}$ for $30 \mathrm{~s}$. All PCR products were electrophoresed in a $2.0 \%$ agarose gel and visualised by ethidium bromide staining. As positive controls, plasmids expressing DARPP-32 or t-DARPP were generated by PCR amplification of the full-length cDNA derived from gastric cancer tissue and cloning into the BamHI and HindIII sites of pCEP4 (Invitrogen Corp., Carlsbad, CA, USA).

\section{Western blot}

Western blot analysis was performed to analyse DARPP-32 and tDARPP expression in oesophageal cancer cell lines. Cell lysates were prepared in SDS buffer containing $62.5 \mathrm{~mm}$ Tris- $\mathrm{HCl}$ pH6.8, $2 \% \mathrm{w} \mathrm{v}^{-1}$ SDS, $10 \%$ glycerol, $50 \mathrm{~mm}$ DTT, $0.1 \% \mathrm{w} \mathrm{v}^{-1}$ bromphenol blue, $1 \mathrm{~mm}$ PMSF. Total proteins ( $40 \mu \mathrm{g}$ : OSCC cell lines, $2 \mu \mathrm{g}$ : tranfected cell lines) were electrophoresed in $15 \%$ SDS-polyacrylamide gels and transferred onto nitrocellulose membranes. Rabbit anti-DARPP polyclonal antibody (H-62; Santa Cruz Biotechnology, Santa Cruz, CA, USA) was used as the primary antibody $(1: 1000)$. Peroxidase-conjugated goat $\mathrm{F}\left(\mathrm{ab}^{\prime}\right)_{2}$ anti-rabbit IgG (Jackson ImmunoReserch, West Grove, PA, USA) was used as the secondary antibody $(1: 5000)$. Detection of bound antibodies was performed using the ECL system (Amersham, Aylesbury, UK). The plasmids expressing DARPP-32 or t-DARPP were transfected into TE8 cells using Lipofectamine (Invitrogen Corp.) and these lysates were used as positive controls.

\section{Patients and oesophageal specimens}

All complete OSCC surgical specimens resected from 1989 to 1999, from patients with no evidence of metastasis to other organs and without prior anticancer treatment, were examined. Cases of inhospital death were excluded. Surgical specimens from 122 patients who had undergone radical oesophagectomy at the Department of Surgical Oncology, Hokkaido University, Hokkaido Gastroenterology Hospital, and Teine Keijinkai Hospital were included in the current study, and findings were referred to the patients' clinical records. One of the sections from the deepest point of each tumour invasion was selected for evaluation. The specimens were examined histologically after staining with $\mathrm{H} \& \mathrm{E}$, and the clinicopathologic stage was determined according to the TNM classification system of the International Union Against Cancer (Sobin and Wittekind, 2002). Specimens from 122 patients were included in the current study (105 males and 17 females). The median patient age was 62.3 years (range, 38-82 years). A relatively large number of patients had early-stage disease (78 patients, $63.9 \%)$. In total, 61 patients $(50.0 \%)$ had lymph node metastases and 19 patients (16\%) had distant nodal metastases. The study population had the following performance status (PS): PS0, 107 patients; PS1, 14 patients; and PS2, one patient. The median follow-up period was 29 months.

All specimens were fixed in $10 \%$ formalin and embedded in paraffin wax. One of the deepest sections from each tumour was selected for evaluation, and serial $4 \mu \mathrm{m}$-thick sections were examined by immunohistochemistry.

\section{Immunohistochemistry}

Unstained sections were treated with a rabbit anti-DARPP polyclonal antibody (H-62; Santa Cruz Biotechnology; 1:200 dilution), using previously described conditions (Oliver and Shenolikar, 1998). Briefly, each slide was deparaffinised by routine techniques, treated with sodium citrate buffer (Ventana-Bio Tek Solutions, Tucson, AZ, USA), and then treated with microwave heat for $20 \mathrm{~min}$. After cooling for $5 \mathrm{~min}$, slides were labeled with antibody using the Ventana EX system automated stainer (Ventana-Bio Tek Solutions). The anti-DARPP-32 antibody was detected by adding biotinylated secondary antibody, avidin-biotin complex and 3, 3'-diaminobenzene (Ventana DAB Universal Kit; Ventana-Bio Tek Solutions). Sections were then counterstained in haematoxylin for $1 \mathrm{~min}$ and mounted in Permount (Microslides; Muto-Glass, Tokyo, Japan). For a negative control, nonimmune purified rabbit serum was used for the primary antibody. The number of stained cells per 1000 was determined under a microscope (Olympus Optical Co., Ltd, Tokyo, Japan) in three visual fields, at a magnification $\times 200$. When microscopic examination indicated that a the total number of cancer cells observed being less than 1000, all cells were counted. When over $10 \%$ cancer cell nuclei and cytoplasm were stained, the tumour was considered DARPP-32 positive. The current study was performed in a retrospective manner, while all specimens were evaluated by three investigators (YE, MM and TI), who were blinded to the patients' clinical information. Dysplasia was defined according to the WHO classification (Stanley and Lauri, 2000).

\section{Statistical analysis}

Either the $\chi^{2}$ test or Fisher's exact test were used to analyse the correlation between DARPP-32 expression and patients' parameters, including histopathologic findings. The Kaplan-Meier method was used to generate survival curves, and survival differences were analysed with the log-rank test, based on the status of DARPP-32 expression. Univariate and multivariate analyses of DARPP immunoreactivity and clinicopathological features were performed using the Cox proportional hazard regression model. Probability values of less than 0.05 were regarded as indicating significance. All analyses were performed using statistical analysis software (Statview J version 5.0; SAS Institute Inc., Cary, NC, USA). 


\section{RESULTS}

\section{Expression of DARPPs in OSCC cell lines}

DARPP-32 RT - PCR fragments were amplified from four out of seven cell lines, while t-DARPP fragments were not amplified in any cell lines (Figure 1A). Western blot analysis showed that a $32 \mathrm{kDa}$ protein, corresponding to DARPP-32, was expressed strongly in TE2 and TE13, while t-DARPP protein $(30 \mathrm{kDa})$ was not detectable in any cell lines, as expected based on the RT-PCR data (Figure 1B).

\section{Detection of DARPPs in human tissues}

In oesophageal sample tissues, DARPP-32 RT-PCR fragments were amplified from four out of seven tumour tissues, but not from any normal oesophageal mucosa. As in the cell lines, t-DARPP RT-PCR fragments were not amplified from any sample tissues (Figure 2).

\section{Immunohistochemical analysis}

We subsequently performed immunohistochemical analysis on the 122 OSCC specimens. This analysis provides suggestions as to the biological function of DARPP in OSCC. DARPP immunoreactivity was observed at the cancer cell membrane and cytoplasm, as seen in a previous study (Wa'el et al, 2002). DARPP was expressed in normal oesophageal gland cells (Figure $3 \mathrm{~A}$ ) and gangliocytes (Figure $3 \mathrm{~B}$ ), permitting their use as a positive internal control. No DARPP expression was detected in normal oesophageal mucous membrane (Figure 3C). In tumour cells, immunoreactivity was

\section{A}

TE2 TE5 TE8 TE10 TE13 HEC46 SGF7 P.C.

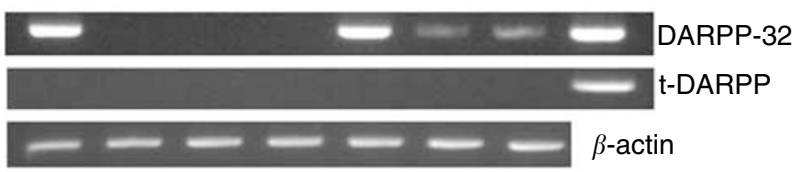

B

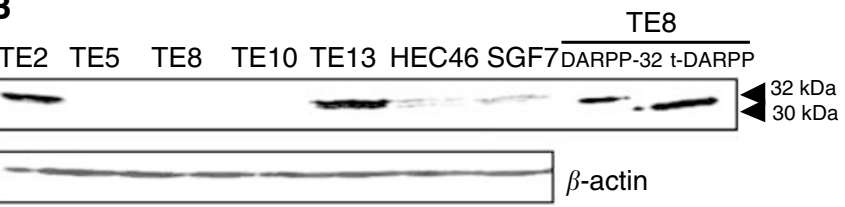

Figure I RT-PCR expression analyses. (A) A gel imaging for DARPP32, t-DARPP and $\beta$-actin expression at 30 cycles by RT-PCR. Seven oesophageal squamous cell lines, and positive controls (pCEP4-DARPP-32, PCEP4-t-DARPP) are shown. (B) DARPP protein expression. Seven oesophageal squamous cell lines and TE8 cells transfected with pCEP4DARPP and pCEP4-t-DARPP were separated by SDS-PAGE and analysed for DARPP protein expression by Western blot with a $\mathrm{COOH}$-terminal DARPP-32 antibody (Santa Cruz Biotechnology).

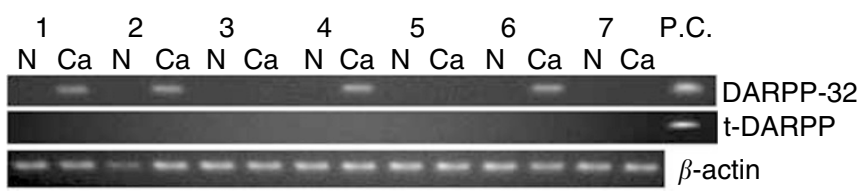

Figure 2 RT-PCR expression analyses. A gel imaging for DARPP-32, tDARPP and $\beta$-actin expression at 30 cycles by RT-PCR. Seven different samples of normal oesophageal mucosa $(N)$, tumour tissues $(\mathrm{Ca})$ and positive control (pCEP4-DARPP-32, pCEP4-t-DARPP) are shown.
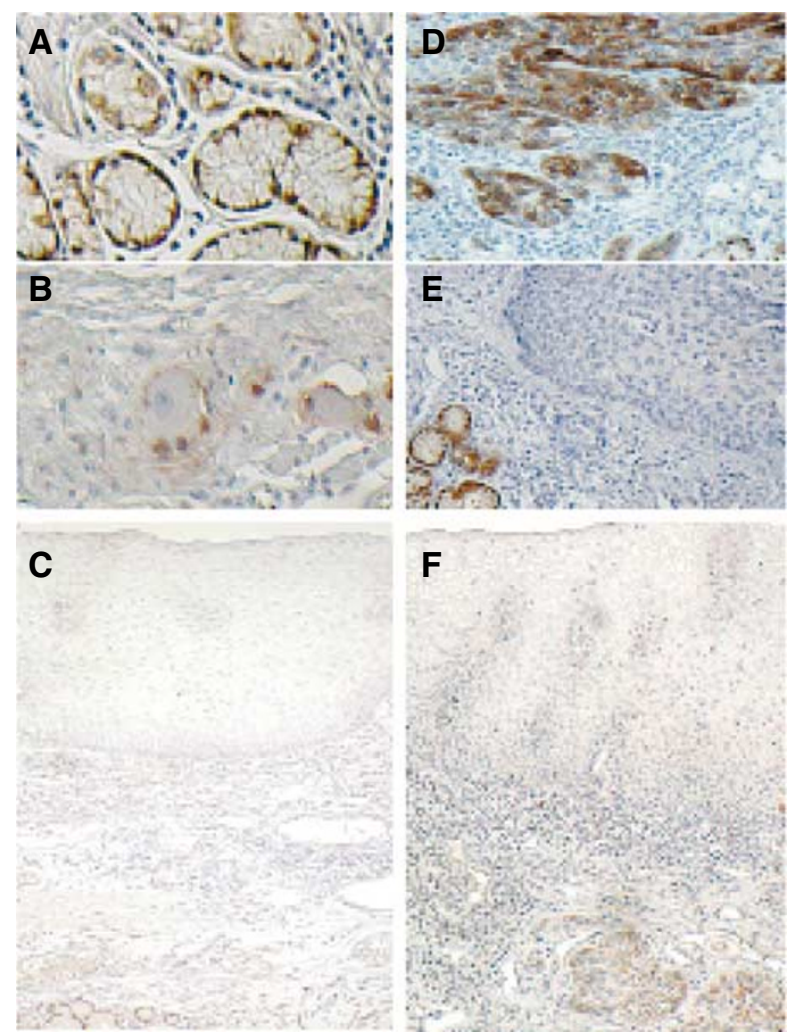

Figure 3 Immunohistochemical staining for DARPP. (A) Oesophageal gland cells, (B) gangliocytes stained as an internal control. (C) DARPP expression is not detected in normal oesophageal mucous membrane. (D) Almost all the cancer cell membrane and cytoplasm were stained for DARPP. (E) DARPP immunoreactivity was not observed in cancer cells, while gland cells showed strong staining as an internal control. (F) DARPP immunoreactivity was not observed in dysplastic cells, while cancer cells showed staining. (original magnifications: A, B, $\times 400$; C, $\times 40$; D, E, $\times 100 ; \mathbf{F}, \times 40)$

observed very vividly (Figure 3D), with 37 patients (30.3\%) staining positive for DARPP and 85 patients (69.7\%) staining negative (Figure 3E).

Dysplasias were found in 45 of 122 specimens, but DARPP expression was only observed in one of theses lesions. A total of 36 patients with DARPP-positive tumours had DARPP-negative dysplasias (Figure $3 \mathrm{~F}$ ).

\section{Statistical analyses between DARRP expression and clinicopathological data}

DARPP immunoreactivity had an inverse relationship with pathologic stage, $\mathrm{pT}, \mathrm{pN}$ and tumour size by the $\chi^{2}$ test (Table 1 ). Moreover, overall survival rate by the Kaplan-Meier method was worse in patients with DARPP-32-negative tumours than in patients with DARPP-32-positive tumours (Figure 4). Upon univariate analysis with Cox proportional hazards model, DARPP immunopositivity was inversely correlated with poor prognosis, although, multivariate analyses did not indicate that DARPP positivity was significant (data not shown).

\section{DISCUSSION}

DARPPs are frequently expressed in gastric cancer. To assess the biological significance, we screened for DARPP expression in 
Table I Relationship between clinicopathologic features and DARPP-32 expression in surgical specimens of oesophageal squamous cell carcinoma

\begin{tabular}{|c|c|c|c|}
\hline Variables & $\begin{array}{c}\text { DARPP-32 } \\
\text { positive }(n=37)\end{array}$ & $\begin{array}{c}\text { DARPP-32 } \\
\text { negative }(n=85)\end{array}$ & $P$ value $^{\mathrm{a}}$ \\
\hline \multicolumn{4}{|l|}{ Gender } \\
\hline Male & 32 & 73 & 0.9294 \\
\hline Female & 5 & 12 & \\
\hline \multicolumn{4}{|l|}{ Age } \\
\hline$\geqslant 65$ & II & 38 & 0.1209 \\
\hline$<65$ & 26 & 47 & \\
\hline \multicolumn{4}{|l|}{ p-Stage } \\
\hline I, ॥ & 29 & 49 & 0.0284 \\
\hline III, IV & 8 & 36 & \\
\hline \multicolumn{4}{|l|}{ Grade } \\
\hline $\mathrm{Gl}$ & 11 & 20 & 0.4696 \\
\hline Others & 26 & 65 & \\
\hline \multicolumn{4}{|c|}{ p-T classification } \\
\hline TI, T2 & 26 & 43 & 0.0438 \\
\hline T3, T4 & II & 42 & \\
\hline \multicolumn{4}{|c|}{ p-N classification } \\
\hline No & 24 & 37 & 0.0303 \\
\hline $\mathrm{NI}$ & 13 & 48 & \\
\hline \multicolumn{4}{|c|}{ p-M classification } \\
\hline MO & 31 & 72 & 0.8973 \\
\hline $\mathrm{MI}$ & 6 & 13 & \\
\hline \multicolumn{4}{|l|}{ Tumour size } \\
\hline$\geqslant 4.5 \mathrm{~cm}$ & 13 & 51 & 0.0115 \\
\hline$<4.5 \mathrm{~cm}$ & 24 & 34 & \\
\hline \multicolumn{4}{|c|}{ Surgical margin } \\
\hline Positive & 2 & 6 & 0.7345 \\
\hline Negative & 35 & 79 & \\
\hline \multicolumn{4}{|c|}{ Adjuvant therapy } \\
\hline Yes & 17 & 33 & 0.4622 \\
\hline No & 20 & 52 & \\
\hline
\end{tabular}

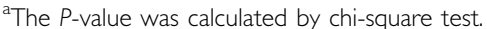

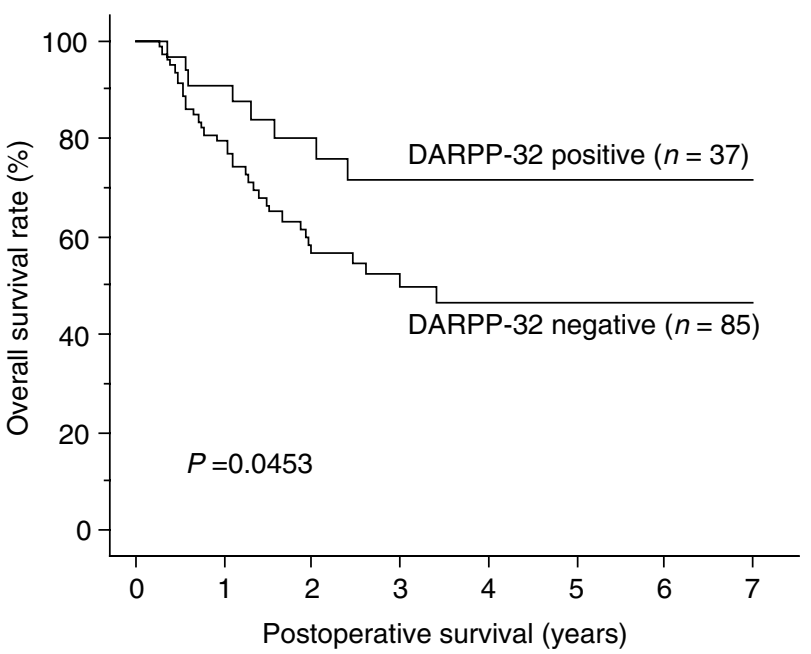

Figure 4 Comparison of overall survival curves for patients with DARPP-32-positive and -negative tumors out of 122 patients who underwent radical oesophagectomy. several types of cancer cell lines. Interestingly, we found that there were two types of OSCC cell lines, DARPP-expressing and nonexpressing cells.

The RT-PCR results appear to accurately reflect the status of DARPP expression. Although both DARPP isoforms were frequently overexpressed in gastric cancer, $30 \%$ of OSCC samples expressed DARPP-32 alone. Based on our RT-PCR and Western blot data, we believe that DARPP immunoreactivity in OSCC specimens is specific to DARPP-32 but not t-DARPP.

In TE2 and TE13 cell lines, manual sequencing analyses were performed, but no genetic alterations of DARPP-32 were found (figure not shown). Therefore, the difference in DARPP-32 expression is not likely to be caused by mutation.

Several reports have described the pattern of progression from normal mucous to dysplasia, to carcinoma in situ (Shi et al, 1999; Saeki et al, 2002; Shirai et al, 2002). Oesophageal dysplasia is also believed to be one of the precursors for OSCC. The ratio of DARPP immunopositivity in dysplasia was significantly lower $(P<0.0001$; $\chi^{2}$ test) compared to that in tumour. These data suggest that overexpression of DARPP arises at the late phase of neoplastic progression of the oesophagus. Moreover, these features could be an advantage to distinguish between cancer and dysplasia in diagnosis of biopsy specimens (30.3\% sensitivity, $97.8 \%$ specificity).

It remains unclear whether DARPP-32 is an oncogene like ras, myc and src because some normal tissue expresses DARPP-32. Overexpression of DARPP-32, however, is related to carcinogenesis in $30 \%$ of OSCC. Moreover, DARPP-32-positive tumours appear to have a less aggressive character than DARPP-32 negative tumours. This characteristic is not due to exclusion by the host immune response. We previously reported that the cooperative role of $\mathrm{CD}^{+}{ }^{+}$and $\mathrm{CD} 8{ }^{+} \mathrm{T}$ cells appears to drastically improve the prognosis of patients with OSCC (Cho et al, 2003). Despite the better prognosis in patients with DARPP-32-positive tumours, the expression of DARPP-32 in OSCC was not correlated with infiltration of $\mathrm{CD}^{+}$and/or $\mathrm{CD}^{+} \mathrm{T}$ cells $\left(P=0.7409 ; \chi^{2}\right.$ test $)$.

DARPP-32 is a known protein that acts as a PP1 inhibitor or an MAPK, CREB mediator. Protein phosphatase 1 and other protein phosphatases that reverse the action of cyclin-dependent kinases are emerging as important cell cycle regulatory enzymes (Oliver and Shenolikar, 1998; Schonthal, 2001; Wang et al, 2001). Many oncogenes have been shown to encode proteins that trasmit mitogenic signals upstream of the MAPK pathway (Seger and Krebs, 1995; Sebolt-Leopold, 2000). Phosphorylation of CREB generates signals that inhibit apotosis (Jean et al, 1998; Jean and Bar-Eli, 2000). Control of phosphorylation in gastrointestinal malignancies has recently been reported as an important mechanism for some neoplasia (Saha et al, 2001; Higashi et al, 2002). To understand the potential role of DARPP-32 in human OSCC, however, additional studies and biological assays are required. We are now proceeding with further investigation to clarify the biological function of DARPP-32 in OSCC cells.

We conclude that DARPP-32 expression arises after a phase of dysplasia in OSCC. Moreover, DARPP-32-positive tumours have a less aggressive character than those that are not.

\section{ACKNOWLEDGEMENTS}

We appreciate the contributions of Mr Hiraku Shida and Ms Akiko Yagi for their technical support in immunohistochemistry, and of the many physicians who cared for patients at the affiliated hospitals of Surgical Oncology. 


\section{REFERENCES}

Ando N, Iizuka T, Kakegawa T, Isono K, Watanabe H, Ide H, Tanaka O, Sinoda M, Takiyama W, Arimori M, Ishida K, Tsugane S (1997) A randomized trial of surgery with and without chemotherapy for localized squamous carcinoma of the thoracic esophagus: the Japan Clinical Oncology Group Study. J Thorac Cardiovasc Surg 114: 205-209

Ando N, Ozawa S, Kitagawa Y, Shinozawa Y, Kitajima M (2000) Improvement in the results of surgical treatment of advanced squamous esophageal carcinoma during 15 consecutive years. Ann Surg 232: $225-232$

Bibb JA, Snyder GL, Nishi A, Yan Z, Meijer L, Fienberg AA, Tsai LH, Kwon YT, Girault JA, Czernik AJ, Huganir RL, Hemmings Jr HC, Nairn AC, Greengard P (1999) Phosphorylation of DARPP-32 by Cdk5 modulates dopamine signalling in neurons. Nature 402: 669-671

Cho Y, Miyamoto M, Kato K, Fukunaga A, Shichinohe T, Kawarada, Hida Y, Oshikiri T, Kurokawa T, Suzuoki M, Nakakubo Y, Hiraoka K, Murakami S, Shinohara T, Itoh T, Okushiba S, Kondo S, Katoh H (2003) CD4+ and CD8+ T cells cooperate to improve prognosis of patients with esophageal squamous cell carcinoma. Cancer Res 63: 1555-1559

Collard JM, Otte JB, Fiasse R, Laterre PF, De Kock M, Longueville J, Glineur D, Romagnoli R, Reynaert M, Kestens PJ (2001) Skeletonizing en bloc esophagectomy for cancer. Ann Surg 234: 25-32

Greengard P (2001) The neurobiology of slow synaptic transmission. Science 294: $1024-1030$

Higashi H, Tsutsumi R, Muto S, Sugiyama T, Azuma T, Asaka M, Hatakeyama M (2002) SHP-2 tyrosine phosphatase as an intracellular target of Helicobacter pylori Cag A protein. Science 295: 683-686

Jean D, Bar-Eli M (2000) Regulation of tumor growth and metastasis of human melanoma by the CREB transcription factor family. Mol Cell Biochem 212: $19-28$

Jean D, Harbison M, McConkey DJ, Ronai Z, Bar-Eli M (1998) CREB and its associated proteins act as survival factors for human melanoma cells. $J$ Biol Chem 273: $24884-24890$

Oliver CJ, Shenolikar S (1998) Physiologic importance of protein phosphatase inhibitors. Front Biosci 3: $961-972$

Saeki H, Kimura Y, Ito S, Miyazaki M, Ohga T (2002) Biologic and clinical significance of squamous epithelial dysplasia of the esophagus. Surgery 131: $22-27$
Saha S, Bardelli A, Buckhaults P, Velculescu VE, Rago C, Croix BS, Romans KE, Choti MA, Lengauer C, Kinzler KW, Vogelstein B (2001) A phosphatase associated with metastasis of colorectal cancer. Science 294: $1343-1346$

Schonthal AH (2001) Role of serine/threonine protein phosphatase 2A in cancer. Cancer Lett 170: 1-13

Sebolt-Leopold JS (2000) Development of anticancer drugs targeting the MAP kinase pathway. Oncogene 19: 6594-6599

Seger R, Krebs EG (1995) The MAPK signaling cascade. FASEB J 9: $726-735$

Shi ST, Yang GY, Wang LD, Xue Z, Feng B, Ding W, Xing EP, Yang CS (1999) Role of p53 gene mutations in human esophageal carcinogenesis: results from immunohistrochemical and mutation analysis of carcinomas and nearby non-cancerous lesions. Carcinogenesis 20: $591-597$

Shirai N, Tsukamoto T, Yamamoto M, Iidaka T, Sakai H, Yanai T, Masegi T, Lawrence AD, Tatematsu M (2002) Elevated susceptibility of the p53 knockout mouse esophagus to methyl- $N$-amylnitrosamine carcinogenesis. Carcinogenesis 23: $1541-1547$

Sobin LH, Wittekind Ch (eds) (2002) UICC TNM Classification of Malignant Tumors, 6th edn. New York: John Wiley

Stanley RH, Lauri AA (eds) (2000) Pathology and Genetics of Tumours of the Digestive System. Lyon: IARC Press

Wa'el ER, Michael Jr FS, Guolian Li, Andy B, Virginia SC, Elizabeth M, Sakari K, Christopher AM, Henry Jr FF, Steven MP (2002) Gastric cancers overexpress DARPP-32 and a novel isoform, t-DARPP. Cancer Res 62: $4061-4064$

Wang RH, Liu CW, Avramis VI, Berndt N (2001) Protein phosphatase 1ámediated stimulation of apoptosis is associated with dehosphorylation of the retinoblastoma protein. Oncogene 20: 6111-6122

Wong H, Anderson WD, Cheng T, Riabowol KT (1994) Monitoring mRNA expression by polymerase chain reaction: the 'primer-dropping' method. Anal Biochem 223: $251-258$

Yan Z, Feng J, Fienberg AA, Greengard P (1999) D(2) dopamine receptors induce mitogen-activated protein kinase and camp response elementbinding protein phosphorylation in neurons. Proc Natl Acad Sci USA 96: $11607-11612$ 